\title{
- \\ Dispositivos de repressão e varejo do tráfico de drogas: reflexões acerca do Racismo de Estado
}

\author{
Priscila Cravo Vianna \\ Claudia Elizabeth Abbês Baêta Neves \\ Universidade Federal Fluminense
}

\begin{abstract}
Resumo
O propósito deste texto é analisar a repressão exercida sobre o varejo do tráfico de drogas a partir do conceito de Racismo de Estado formulado pelo filósofo francês Michel Foucault. As práticas de repressão ao tráfico de drogas têm se legitimado por ações geopolíticas que se dirigem, primordialmente, ao tráfico varejista com bases de apoio em favelas e comunidades desassistidas de políticas públicas e sociais, e de modo menos incisivo aos grandes traficantes e demais facilitadores. Tal geopolítica contemporânea das ações estatais de repressão e seus aparatos intermediários, entre eles a mídia, sugerem uma tripla função, qual seja: a legitimação de práticas de violência e extermínio direcionadas à população pobre, a produção de uma subjetividade potencialmente perigosa atrelada à pobreza e a regulamentação e legitimação da descartabilidade destas vidas em prol de uma guerra justa pela segurança e pela paz.
\end{abstract}

Palavras-chave: tráfico de drogas; racismo de estado; biopolítica.

\begin{abstract}
Repression devices and drug retailer traffic: reflections about the State Racism. The purpose of this article is to investigate how the repression against the drug retailer traffic is related to the notion of State Racism as formulated by the French philosopher Michel Foucault. The repression against the traffic, specially directed to the retailer traffic with bases of support in slums, and not to the big traffickers and others facilitators, suggests that its principal function is to legitimate practices of violence and extermination directed to the poor population. This text discusses the periculosity stigma often vinculed to the poverty, with the objective of understand the reasons that made possible the legitimization and the trivialization of these practices.
\end{abstract}

Keywords: drug traffic; state racism; biopolitical.

A proposta deste estudo é a de investigar a repressão dirigida ao tráfico varejista à luz do conceito de Racismo de Estado, tal como proposto por Michel Foucault. Em um sentido lato, trata-se de verificar como as políticas voltadas para o enfrentamento do tráfico de drogas no capitalismo contemporâneo servem a mecanismos de extermínio e exclusão legitimados pelas próprias práticas estatais de segurança pública, cuja finalidade última seria a de proteger aqueles que "devem viver" - em outros termos, aqueles que se encontram mais enquadrados e inseridos no mercado de demandas e exigências sociais - daqueles que "devem morrer".

Aqueles que "devem viver" correspondem aos ditos "cidadãos de bem", pagadores zelosos de seus impostos, respeitadores da lei e da ordem, potenciais consumidores de estilos e modos de vida "civilizados". Em contrapartida, seu oposto equivale àqueles a quem se "deixa morrer", ou se "faz" morrer: os que respondem por condutas marginais ou desviantes, apresentando-se, assim, como um perigo para os cidadãos de bem. Atualmente temos podido perceber que essa finalidade tem se (des)regulamentado ou modulado, justificando mesmo a morte dos chamados enquadrados - os que devem viver - se estas forem em prol do extermínio dos marginais do tráfico, dos ditos terroristas, operando uma lógica dos fins que justificam os meios e os acidentes de percurso que diariamente aparecem na mídia. O Racismo de Estado constitui, em última análise, a medida deste perigo: matar para não morrer.

Não há nessas considerações nenhuma intenção de vitimização, infantilização e/ou glamourização dos traficantes pobres, pois estes, em grande parte, também (re)produzem e afirmam em suas práticas e relações com a comunidade na qual se inserem modulações dessa mesma lógica: uma guerra-justa para fazer morrer aqueles que os impedem de expandir e acumular (seja tratando-se de poder, status e/ou acesso ao consumo de determinados estilos de vida) - especialmente traficantes de 
outras facções, traidores, devedores e agentes repressivos do Estado. Interessa-nos neste artigo marcar as linhas de força que dão sustentação a tais lógicas de repressão em suas diferentes modulações produtoras do Racismo de Estado em nós.

A fim de situarmos a questão da repressão ao tráfico varejista de drogas em relação ao Racismo de Estado, faz-se necessária uma exposição teórica acerca deste conceito, à luz das contribuições do filósofo Michel Foucault. Articulado a noções centrais que atravessam sua obra - como biopoder e biopolítica - o Racismo de Estado, especialmente na medida em que se vincula a mecanismos de punição e extermínio, representa um dispositivo fundamental para o funcionamento de sociedades capitalistas em "estado de exceção permanente" (Agamben, 2003), capazes de sancionar o direito de matar.

\section{Direitos sobre a vida e a morte, biopoder e biopoliti- $c a$}

O direito de matar (ou direito de vida e de morte) foi por um longo tempo, segundo Foucault (1976/1990), um dos elementos mais representativos do poder soberano. A singularidade do direito de vida e de morte do soberano reside no fato de este só se exercer como "réplica", como "resposta a uma ofensiva contra o soberano", e não contra os seus súditos.

Foucault (1976/1990, 2005) assinala o caráter assimétrico desse direito de vida e de morte. O rei não é capaz, obviamente, de "dar a vida". Efetivamente, seu poder se realiza por sua capacidade de "provocar a morte". É um poder que em realidade pouco se ocupa da vida, ocupando-se, no máximo, em poupá-la, em "deixar viver". Em tal economia de poder punitivo, o crime é também o "crime cometido efetivamente contra o soberano". Apenas a punição do criminoso poderia recuperar o poder soberano afrontado, devendo corresponder à vingança soberana, materializada na punição grotesca e atroz. Nessa dinâmica do poder, a expiação do crime nada mais é que a demonstração do poder soberano. Era basicamente disso que o crime se tratava até então: o criminoso em si ou a natureza do crime não eram problematizados.

O interesse sobre os mesmos aparece, para Foucault (2002), por volta do século XVIII, vinculado a uma nova economia dos mecanismos de poder. Um poder que, destacado do princípio arbítrio do soberano, se realiza de forma ainda mais incisiva, exercendo-se de forma cada vez mais contínua e rigorosa, abarcando um plano muito mais extenso de incidência, ao mesmo tempo de maneira otimizada e menos custosa. Tal majoração dos efeitos de poder assinala um redimensionamento das suas técnicas, notadamente na medida em que este começa a se "interessar pela vida". Esse redimensionamento assinala o interesse pela vida (ou pelo homem) primeiramente enquanto corpo individual a ser disciplinado e utilizado, e posteriormente, também, em relação ao homem enquanto ser-vivo, enquanto espécie. Conforme nos aponta Foucault (2005), até os séculos XVII e XVIII, as técnicas de poder centravam-se principalmente no corpo individual, com objetivos pragmáticos de controle e utilização da sua força útil mediante uma série de novos dispositivos. Tais dispositivos incluíam técnicas de vigilância que garantissem a visibilidade destes corpos, que deveriam ser continuamente mapeados e supervisionados por intermédio de inspeções, relatórios e graus hierárquicos, a fim de serem devidamente regrados e "disciplinados". A essas técnicas de enquadramento que se efetuavam sobre os homens na medida em que estes eram corpos, cujo exercício era delimitado por muros institucionais, Foucault denomina "técnicas disciplinares".

A partir da metade do século XVIII, tal configuração vai passando por transformações. Aqui, Foucault (2005) localiza uma nova tecnologia de poder, a qual "não suprime a técnica disciplinar simplesmente porque é de outro nível, está noutra escala, tem outra superfície de suporte e é auxiliada por instrumentos totalmente diferentes" (Foucault, 2005, p. 289). Pelo contrário, as complementa e potencializa. É neste contexto que as técnicas de poder se voltam para o homem como "ser vivo". O poder se ocupa então da "gerência própria da vida", e se configura como biopolitica.

É neste momento que a Psiquiatria insurge como um ramo especializado da higiene pública voltado para a proteção social com vistas a proteger a sociedade dos loucos perigosos. Com os novos dispositivos de vigilância e a emergência da Psiquiatria, o século XVIII viu o engendramento de uma nova e intrincada rede de controle suplementada pelo aparelho de justiça e pela polícia, responsável por não deixar escapar qualquer ato criminoso. A tecnologia de punição passa também por uma inovação: ao crime não se responde mais com a vingança soberana, e sim “com a própria medida do crime", acrescida da garantia de que aquele crime não se repetirá. A base do cálculo para a ação da justiça passa a ser então a inteligibilidade do crime, aquilo o torna compreensível a partir de um fundo de racionalidade "imanente à conduta criminal" (Foucault, 2002, p. 111). Definida essa nova economia de punição, a atenção finalmente recai sobre a natureza do criminoso. A questão passa a girar especialmente em torno dos mecanismos que tornam possível a existência de um interesse cuja veemência torna um homem capaz de se sobrepor aos interesses de todos os outros, e no limite, aos seus próprios interesses, na medida em que aquele que comete um crime intui poder esperar como consequência do seu ato uma punição. Arriscar-se de tal forma só poderia corresponder a uma motivação violenta, imprópria, um "instinto excessivo, perigoso, anormal".

Como tornar passível de intervenção legal condutas que por si mesmas não comportam nenhum critério de razoabilidade, excetuando-se os casos de loucura detectável que garantem a inimputabilidade do autor? A solução encontrada pela psiquiatria legal diante de tal dilema foi atribuir crimes como estes aos instintos excessivos. O criminoso seria aquele que, por definição, possuiria uma força instintiva excessiva, que deveria ser devidamente controlada.

É assim que se consolida, então, a junção da Psiquiatria com as teses evolucionistas: no século XIX a Psiquiatra encontra-se associada a uma tecnologia eugênica, entendida como purificação da raça, que deve se precaver daqueles portadores deste instinto desviado. E uma vez que a própria noção de instinto remete a elementos intrínsecos em relação a um indivíduo, a conclusão que se chega é óbvia: os criminosos são criminosos por natureza.

Entretanto, eis que surge então um novo paradigma acerca dos objetos de psiquiatrização (apesar de não anular o anterior). No lugar dos instintos excessivos que irrompem de forma mais ou 
menos pontual, surge uma "psiquiatria de estado permanente, um estado permanente que garante um estatuto definitivo aberrante" (Foucault, 2002, p. 380). É a atribuição definitiva e irrefutável de que um indivíduo seria predisposto ao crime, em função de uma condição inalienável que o define. A noção de exagero instintivo não dá mais conta dos domínios sobre os quais a Psiquiatria pretende então arguir. É tendo em vista esta configuração de coisas que Foucault sinaliza para uma notável inflexão no saber psiquiátrico, a partir do surgimento da noção de Estado:

O estado é uma espécie de fundo causal permanente, a partir do qual podem se desenvolver certo número de processos, certo número de episódios que, estes sim, serão precisamente a doença. Em outras palavras, o estado é a base anormal a partir da qual as diferenças se tornam possíveis.... Quem é sujeito a um estado, quem é portador de um estado, não é um indivíduo normal. (Foucault, 2002, p. 397)

A questão que emerge então é: o que configura esse estado de onde se torna possível para a Psiquiatria abstrair as condutas desviantes? A resposta imediata é: hereditariedade. De acordo com a tese da hereditariedade descrita por Foucault (2002), uma condição tida como patológica ou desviante referente a um indivíduo pode servir como matriz de outras condições adversas para seus descendentes. Trata-se da atribuição de uma relação de causalidade entre hereditariedade e desvio, na medida em que o estado que predispõe o indivíduo a uma determinada conduta ou patologia é entendido como resultante de uma determinada configuração hereditária, biológica.

Contemporânea à tese da hereditariedade e complementando-a, Foucault (2002) sinaliza também para a tese da degeneração. Em um sentido lato, tal tese sustenta o princípio de que uma vez que um indivíduo seja portador de algum traço anormal, este irá desenvolver-se em um processo de deterioração inexorável. Finalmente, a incorporação das teses eugênicas, evolucionistas, das teorias sobre o estado e da degeneração vão consolidar a vinculação da Psiquiatria com o racismo - não, conforme sinaliza Foucault (2002), um racismo do tipo étnico, tradicional, ainda que estes elementos estejam presentes - um racismo mais geral contra aquilo que se desvia da norma, e, portanto, daqueles que são portadores do perigo. É um racismo

contra o anormal, é o racismo contra os indivíduos, que, sendo portadores seja de um estado, seja de um estigma, seja de um defeito qualquer, podem transmitir a seus herdeiros, de maneira mais aleatória, as conseqüências imprevisíveis do mal que trazem em si, ou antes, do não-normal que trazem em si....Racismo interno, racismo que possibilita filtrar todos os indivíduos no interior de uma sociedade dada. (Foucault, 2002, p. 403)

A problemática do anormal articula-se, em tempos de biopolítica, a um outro elemento: a população. O poder dirige-se então para problemas pertinentes no nível da massa, problemas estes que incidem globalmente e de forma aleatória, incluindo a questão da anormalidade, das condutas atreladas ao status de anormal, que vinculam a doença com o crime, o desvio.

Assim, o direito de vida e de morte sofreu profundas alterações no decorrer do século XIX (Foucault, 2005). Se antes era uma questão de fazer morrer e deixar viver por conta da vontade soberana, este princípio sofre uma transformação: "fazer viver" $e$ "deixar morrer". Trata-se de uma biorregulamentação: se antes a vida não era um objeto privilegiado do alvo do poder, que se ocupava dela apenas para usurpá-la, agora representa um foco fundamental e estratégico, a tal ponto que o investimento e a atenção sobre a vida se constituem como sustentáculos deste biopoder. Emergem, então, os saberes sobre o sujeito, sobre o corpo, instrumentalizados em práticas de intervenção sobre a população. Investimento, portanto, na medida em que se apodera da vida, em que se ergue em função de torná-la mais divertida, mais saudável, mais segura, mais bonita e mais prazerosa. Investimento da vida pelo poder porque "este sempre tem algo a dizer sobre aquela", sempre tem uma resposta a dar ou uma novidade a oferecer. Investimento conforme se consolidam saberes com vistas justamente a darem conta desses objetivos específicos.

Em um contexto onde o poder se volta para a vida de tal forma, como preservar também o direito de morte? Como inserilo sem recair em contradição com a lógica de investimento da vida? A estas questões, Foucault (2005) responde: com o racismo. É o racismo que pode, dentro desta lógica, balizar o direito de matar, pois ele se justifica em favor daqueles que devem viver - mata-se, portanto, em nome da vida. $\mathrm{O}$ racismo torna possível "para um poder político, matar, pedir a morte, mandar matar, dar a ordem de matar, expor à morte não só seus inimigos, mas mesmo os seus próprios cidadãos" (Foucault, 2005, p. 304).

No plano de gerência da vida e da regulamentação da população, ou biorregulamentação, é o racismo que estabelece o corte entre quem deve viver e quem se deixa (ou faz) morrer. Este racismo, de acordo com Foucault (2005), cumpriria duas funções. A primeira delas seria criar defasagens entre os grupos que compõem a população, mediante a sobrecodificação de uns como superiores e outros como inferiores. A segunda seria o estabelecimento de uma relação guerreira - "se você quer viver, é preciso que você faça morrer, é preciso que você possa matar" (Foucault, 2005, p. 305), que no contexto do biopoder é reformulada em:

uma relação do tipo biológico: "quanto mais as espécies inferiores tenderem a desaparecer, quanto mais os indivíduos anormais forem eliminados, menos degenerados haverá em relação à espécie, mais eu - não enquanto indivíduo, mas enquanto espécie - viverei, mais forte serei, mais vigoroso serei, mais poderei proliferar". A morte do outro não é simplesmente a minha vida, na medida em que seria minha segurança pessoal; a morte do outro, a morte da raça ruim, da raça inferior (ou do degenerado, ou do anormal) é o que vai deixar a vida em geral mais sadia; mais sadia e mais pura. (Foucault, 2005, p. 305)

Sob esse prisma biológico, fica cada vez mais nítido o produto da articulação entre as teses evolucionistas e as tecnologias de poder. Os inferiores, degenerados, pouco evoluídos, devem perecer. É assim que o evolucionismo não apenas colocou em termos biológicos (e também científicos) o discurso político (biopolítico), mas também se constituiu como "uma maneira de pensar as relações de colonização, a 
necessidade de guerras, a criminalidade, os fenômenos da loucura e da doença mental, a história da sociedade com suas diferentes classes, etc." (Foucault, 2005, p. 307)

Interessa-nos aqui, sobretudo, a questão da criminalidade, tomando como recorte o problema do tráfico de drogas e a imagem do traficante. Evolucionismo, racismo, dever morrer em nome de outros que devem viver são elementos que se cruzam nesta problemática.

\section{A repressão no varejo: um recorte do Racismo de Estado em sociedades como a nossa}

Quem são os traficantes? Como deveria responder (ou como efetivamente responde) o Estado diante do problema em torno do tráfico? Estas não são questões simples de serem respondidas, e por isso não devem admitir respostas rápidas e levianas. Entretanto, ao se falar em "traficante", a imagem imediatamente evocada é bastante banal e cotidiana para todos aqueles que assistem à televisão e lêem os jornais: negro, pobre, vestido com camiseta, bermuda e boné, olhar desafiador, ostentando armamentos pesados, residente em áreas periféricas. Cruéis, desumanos, capazes de infligir as piores torturas, pequenos demônios que promovem o vício, a morte; representantes do crime organizado, fortes o bastante para engendrar um estado paralelo e um estado de guerra civil. Em seus territórios, ou suas bases de apoio logístico, valem suas leis arbitrárias, e não as do Estado de Direito. Alguns ainda podem evocar um traço assistencialista na figura do traficante, que teria se apropriado das lacunas deixadas pelo Estado com o fim de alcançar legitimidade e apoio por parte da população local - uma espécie de Robin Hood urbano pós-moderno. O traficante é uma figura mítica, e se confunde com outras figuras que passam cotidianamente ao nosso lado pelas ruas, especialmente nas grandes metrópoles brasileiras. Nesse cenário, é também um inimigo - uma afronta ao Estado e aos seus cidadãos. E a partir do consenso de que o traficante é o inimigo começa a ser delineada a resposta que eles merecem, inclusive por parte do Estado: a anulação, o extermínio, a neutralização, a tolerância zero, os choques de ordem. Matá-los para não sermos mortos; neutralizar suas ações para que a sociedade não mergulhe em vícios imorais e degradantes como as drogas.

Seria assim tão simples? Seriam estas figuras dotadas de tão grande poder? Qual o papel do traficante varejista no interior da hierarquia que estrutura a rede do tráfico de drogas? Por que cada rapaz negro, pobre, funkeiro, vestido de bermuda e boné é passível de despertar tantas suspeitas?

Coimbra e Nascimento (2003) discutem as condições que tornaram possível a emergência do que as autoras denominam mito da periculosidade. Trata-se de um mito que articula periculosidade, falta de humanidade e criminalidade à pobreza, que representa uma instrumentalização clara do Racismo de Estado: por serem pobres, são perigosos; se ainda não fizeram algo efetivamente suspeito, a condição de pobreza indica que há uma predisposição latente para tal esperando apenas o momento propício para se manifestar. Há de se suspeitar sempre dos pobres, e por isso, há de se exercer o controle sobre estes. Retomando os apontamentos de Foucault apresentados no item anterior, trata-se de uma questão de Estado, e a condição de pobreza converte- se em uma espécie de fundo causal permanente, que concorre para a produção do anormal, daquele a quem falta humanidade e por isso não pode ser considerado (e tratado) como humano.

Coimbra e Nascimento (2003) afirmam que "em nosso país, que sofre uma herança de mais de trezentos anos de escravidão, o controle das virtualidades exercerá um papel fundamental na constituição de nossas subjetividades sobre a pobreza" (p. 20). Finda a escravidão, emerge uma população que, sob o desenvolvimento da sociedade industrial, deveria converter-se de mercadoria em mão de obra. E, caso fracassasse, vadiando por aí, deveria ser devidamente controlada para não contaminar com suas mazelas "naturais" o restante da sociedade. De onde viria essa capacidade contaminadora desta massa de ex-escravos?

Já no início do século XIX, conforme apontam as autoras em consonância com os estudos de Foucault - a antropometria, a medição dos ossos, crânios e cérebros tornaram-se populares entre os cientistas, que comparando os dados obtidos, buscavam indícios capazes de comprovar a inferioridade de determinados segmentos sociais (bem como de determinadas raças). Contextualizando este período, é preciso lembrar que:

Para tanto, muito contribuíram algumas teorias - racistas e eugênicas, que emergiram no século XIX na Europa, condenando as misturas raciais e as caracterizando como indesejáveis, produtoras de enfermidades, de doenças físicas e morais (imbecilidades, idiotias, deficiências em geral, indolência, entre outras). É interessante notarmos que, neste mesmo período, ocorrem, também na Europa, movimentos que propugnam e influenciam as propostas de abolição da escravatura negra nas Américas. Ou seja: ao mesmo tempo em que desponta a figura do trabalhador livre... produz-se uma essência para este mesmo trabalhador. (Coimbra \& Nascimento, 2003, pp. 20-21)

A essência que é então atribuída a esta nova massa composta de ex-escravos é a da periculosidade. A miséria "passa a ser naturalmente percebida como advinda da ociosidade, da indolência e dos vícios inerentes aos pobres" (Coimbra \& Nascimento, 2003, p. 21). Neste contexto é que em 1890 aparecem as primeiras referências à aplicação do sistema penal aos vadios. O ócio e a vadiagem são associados à atitude suspeita, à insubordinação, à depravação, enquanto que o trabalho comparece vinculado à dignidade e à honestidade (Batista, 2003). Surgem então as ditas classes perigosas, sobre as quais recai a atenção do sistema criminal. O cientificismo da época apregoava ser necessário livrar a sociedade destes degenerados natos:

Essas teorias racistas e eugênicas foram realimentadas pela obra de Charles Darwin A Origem das Espécies. Conceitos como 'prole malsã', 'herança degenerativa', 'degenerescência da espécie', 'taras hereditárias', 'inferiorização da prole', 'procriação defeituosa', 'raça pura', 'embranquecimento', 'aperfeiçoamento da espécie humana', 'purificação' são comuns em tratados de Medicina, Psiquiatria, Antropologia e Direito no final do século XIX e no início do século XX que apregoam, seguindo o modelo da eugenia, a esterilização dos chamados degenerados como profilaxia para os males sociais". (Coimbra \& Nascimento, 2003, pp. 22-23)

Conforme apontam as autoras, estas teorias repercutem 
no Brasil expressando-se especialmente através do movimento higienista, comprometido com a "higienização da sociedade". Schwarcz (2004), tratando do higienismo no Brasil, levanta que, ao abandonar o indivíduo e se voltar para a sociedade, os médicos higienistas passavam a explicar o fracasso do Brasil pela doença - era preciso, então, entender a causa da doença para tratá-la. É nesse contexto que a eugenia e a questão da raça e da eugenia se revelam no higienismo brasileiro: as doenças teriam vindo da África (com os escravos) ou da Ásia e da Europa (com os imigrantes). A 'mistura de raças' seria responsável pelo enfraquecimento biológico da nação.

$\mathrm{O}$ higienismo não foi um movimento restrito à esfera médica - pulverizou-se por toda a sociedade brasileira, abarcando especialistas das áreas da Pedagogia, da Arquitetura, do Urbanismo, do Direito etc. Assim, tal movimento conseguiu grande amplitude social, ainda que embasado em teorias racistas, no darwinismo social e na eugenia, ao visar o aperfeiçoamento da raça e colocar-se "abertamente contra negros e mestiços, a maior parte da população pobre brasileira" (Coimbra \& Nascimento, 2003, p. 23). A degradação fora atrelada à pobreza, e os higienistas afirmavam que toda a sociedade deveria se engajar na luta contra o mal que se perpetuava dentro desta. Em última instância, livrar-se deste mal implicava livrar-se dos pobres. $\mathrm{O}$ conceito de periculosidade adapta-se perfeitamente a este contexto: a pobreza emerge, efetivamente, como um sinal de perigo, e logo os pobres são "naturalmente" perigosos e "automaticamente" suspeitos, devendo ser "preventivamente controlados".

Com a pobreza atrelada à periculosidade, surgem mecanismos específicos de controle direcionados à população pobre. Aos ditos pobres dignos, que trabalhavam e encontravamse inseridos na lógica capitalista, era necessário reforçar os valores morais, a fim de que os vícios inerentes à pobreza (sempre latentes, ainda que não manifestos) não emergissem e corrompessem a saúde social. Os pobres que não trabalhavam e que viviam no ócio representavam um perigo social a ser erradicado, uma vez que seriam "portadores de delinqüência, libertinos, maus pais e vadios" (Coimbra \& Nascimento, 2003, p. 24).

Em estudo dedicado à criminalização do jovem pobre no Rio de Janeiro, Batista (2003) demonstra que a ação do sistema penal desta época recaíra especialmente sobre aqueles dados à insubordinação e que não teriam "paciência para aturar patrão". Daí que os menores abordados em atitude suspeita, os quais se identificavam como engraxates, entregadores de jornal, vendedores de bilhetes de loteria, ou biscateiros, fossem suspeitos, evidenciando que a 'atitude suspeita' não se refere a um "ato" efetivamente suspeito, e sim a "sinais de estigmatização". Situação de abandono, ou ainda, "situação irregular", ou a ausência de uma família estruturada concorriam para a consolidação da suspeição, que, na maior parte das vezes, terminava na internação destes jovens em instituições correcionais, sob a tutela do Estado.

Além da estigmatização atrelada à atitude suspeita, Batista (2003) demonstra em seu estudo a desigualdade de tratamento direcionada aos jovens infratores em função de sua etnia e origem social. Através da análise de outros processos, a autora aponta a lentidão que geralmente caracterizava o processo de julgamento aos quais eram submetidos os jovens pobres. Exames demoravam a ser feitos e audiências demoravam a ser marcadas, de modo que o período de internação antes do parecer final do juiz alongava-se desnecessariamente. Em contrapartida, chama atenção da autora a rapidez com que estes processos eram julgados em casos envolvendo jovens de classe média e alta, bem como o fato de na maior parte das vezes estes jovens terem seus movimentos restritos, no máximo, à liberdade vigiada. De fato, nos processos analisados pela autora, nenhum destes outros jovens foi submetido à internação.

O mesmo ocorre com as infrações relacionadas ao uso/ tráfico de drogas ocorridas entre 1968 e 1988, na amostragem aleatória analisada por Batista (2003). Enquanto aos jovens de classe média e alta aplicava-se o estereótipo médico, aos jovens pobres aplica-se o estereótipo criminal. A classe média e alta resolve os problemas de seus filhos na esfera privada - nos processos estudados pela autora, o desdobramento mais comum era o comprometimento da família com o tratamento médico dos filhos, solucionando o problema. Já aos jovens pobres reserva-se a entrada direta ao sistema criminal, fosse por traficar, fosse por consumir drogas. Nos processos analisados no período de 1968 a 1988, apenas jovens não-brancos e pobres foram indiciados por portar pequena quantidade de droga para uso próprio, enquanto jovens de classe média aparecem em apenas $11 \%$ dos processos apesar do decreto-lei 385/68 baixado pelo então Presidente Costa e Silva em 1968 modificar o Código Penal de 1940, igualando frente à lei traficantes e usuários.

Nos dias de hoje, a situação ainda persiste. Jovens pobres abordados portando pequena quantidade de droga para consumo próprio são mais facilmente identificados como traficantes, enquanto os de classe média e alta são identificados como os usuários - ainda que a mídia venha noticiando alguns casos de tráfico envolvendo classe média e média alta. É possível verificar (inclusive em inúmeros meios de comunicação em massa) a presença da discussão acerca da descriminalização do uso de drogas (especialmente a maconha) e mesmo alguns avanços legislativos no tratamento para com o usuário, mas não se debatem mudanças legislativas no sentido de requalificar a caracterização do que seria tráfico, e, por conseguinte, de reconfigurar a repressão direcionada aos acusados de tráfico que se inscrevem mais como usuários do que como traficantes. Ao contrário, as leis vêm se tornando cada vez mais duras, a repressão, mais intensiva e o controle, mais incisivo. Se no período ditatorial o tráfico fora enquadrado como crime contra a Segurança Nacional, a Constituição de 1988 o equipara ao crime hediondo, inafiançável, sem direito à graça ou anistia. A edição da Lei de Crimes Hediondos (Lei 8.072/90)ํำ de 1990 inviabiliza aos condenados o direito de liberdade provisória, indulto e progressão de regime, além de ampliar os prazos para prisão temporária e livramento condicional, enquanto que a Lei do Crime Organizado (Lei 9.034/95) inspirada no modelo normativo italiano de repressão às organizações mafiosas, "trata-se nitidamente de uma legislação de emergência baseada na legislação italiana de exceção" (Carvalho, 2006, p. 58, grifo nosso), indo de encontro às garantias constitucionais que balizam o Estado de Direito. Trata-se de uma lei com nítidas nuances 
inquisitoriais, que cria amplas possibilidades de acesso a dados fiscais, bancários, financeiros, eleitorais, além da interceptação de sinais magnéticos, óticos ou acústicos. Determina, também, a identificação criminal compulsória, premia a delação, proíbe a liberdade provisória com ou sem fiança e nega a possibilidade de apelo em liberdade (Carvalho, 2006). A seletividade da punição em relação aos crimes vinculados à questão das drogas continua firme, e a maior parcela da repressão recai ainda sobre jovens pobres - especialmente se considerarmos que o tráfico vem recrutando sua mão-de-obra entre uma população cada vez mais jovem, conforme assinala Batista (2003).

É neste panorama que a grande mídia compromete-se com a produção da imagem demonizada do traficante e do usuário através da superexposição e da super exploração de episódios de violência vinculados ao uso e tráfico de drogas - filhos que matam os pais sob uso de drogas, conflitos entre traficantes e policiais, inclusive ocasionando grande número de vítimas, muitas vezes, não diretamente envolvidas com o tráfico, etc. produzindo na população sentimentos de indignação e medo que a leva a demandar políticas públicas extensivas de segurança e de punição (vide o apoio de parte significativa da população à política de "tolerância zero", à criação de milícias, aos caveirões, além dos recentes debates sobre pena de morte e redução da maioridade penal) ${ }^{2}$.

No Brasil dos dias de hoje, as políticas repressoras de combate ao tráfico, justificadas pelas demandas de segurança pública, estabelecem o corte do qual nos fala Foucault (2005) entre quem deve viver e quem deve (ou pode) morrer, configurando as bases que tornam aceitável a prática do Racismo de Estado numa sociedade como a nossa. Este racismo seria o nó górdio destas políticas. Foucault o atribui a prerrogativas como "se você quer viver, é preciso que faça morrer", no qual a segurança vincula-se à anulação de um outro. A forma pela qual a polícia vem realizando seus ataques às favelas, a mídia sensacionalista, o apoio da opinião pública - ou daqueles que querem viver - a estas operações sanguinárias são diretamente atravessadas por este racismo. É sabido que não são apenas os traficantes que se encontram expostos à morte nestas operações, mas também toda a população ao seu redor, geralmente negra, nordestina e pauperizada. O assassínio ocasional de indivíduos não envolvidos com o tráfico é utilizado como desculpa para intensificar ainda mais estas operações, em vez de motivar seu estranhamento. Neste sentido, mesmo estes assassinatos "indiretos" também estão previstos pelas tecnologias racistas de regulamentação, atravessadas pelo "fato de expor a morte, de multiplicar para alguns o risco de morte ou, pura e simplesmente, a morte política, a exclusão, a rejeição, etc.” (Foucault, 2005, p. 306). Assim é que, segundo Foucault, o racismo emerge como condição de aceitabilidade de tirar a vida em uma sociedade de normalização como a nossa e nos dá indícios sobre a enunciação contemporânea de uma "guerra" às drogas.

Os envolvidos com o problema não são afetados da mesma maneira. No interior das políticas antidrogas, é possível verificar que tais medidas repressivas são seletivas, direcionadas a grupos específicos, em uma conveniente "gestão dos ilegalismos". Em termos gerais, a gestão dos ilegalismos se refere não a uma gerência que prima por fazer cumprir a lei incondicionalmente, mas, sim, a uma forma de gestão diferencial em que pode haver maior ou menor tolerância no tocante ao descumprimento das leis, dependendo das variáveis que constituem o ato supostamente ilegal. Daí que a lei, em relação às condutas nas quais incide, constitua

uma gestão dos ilegalismos, permitindo uns, tornando-os possíveis ou inventando-os como privilégio da classe dominante, tolerando outros como compensação às classes dominadas, ou mesmo, fazendo-os servir à classe dominante, finalmente, proibindo, isolando e tomando outros como objeto, mas também como meio de dominação. (Deleuze, 1991, p. 39)

A operacionalização da gestão dos ilegalismos, portanto, é o que possibilita a efetivação da seletividade com que incide a repressão sobre os traficantes varejistas em comparação aos traficantes do atacado e os demais facilitadores do tráfico - de forma análoga à repressão incidente sobre a população pobre em relação às classes médias e altas acerca do uso ou posse de drogas. Sendo assim, tal gestão constitui uma importante função pragmática do Racismo de Estado.

A mitificação do traficante é outro aspecto a ser assinalado, cabendo ressaltar o estereótipo de poder que acompanha a noção de "traficante". Magalhães (2000) destaca que os traficantes mais espetacularizados pela mídia não são, como muitos poderiam imaginar, os maiores traficantes do país ou da cidade. Alcunhas míticas, como Fernandinho Beira-Mar, Uê, Marcinho VP não se referem senão a "gerentões do varejo". O próprio Comando Vermelho, segundo Souza (2005), seria mais uma espécie de cooperativa criminosa que uma estrutura hierárquica rígida nos moldes da máfia.

Classificar o tráfico varejista como crime organizado precipita alguns problemas. Magalhães (2000) e Souza (2005) sinalizam para o fato de que apesar do que é alardeado pela mídia, a articulação entre o movimento nas favelas é mais limitada do que parece. Ao contrário: o tráfico varejista é fragmentado e há uma constante disputa territorial envolvendo os pontos de venda de drogas entre os variados grupos.

Para Souza (2005), a razão pela qual o poder e a organização do tráfico varejista são exagerados reside no interesse em desviar a atenção da opinião pública daqueles que seriam os verdadeiros empresários da droga: os que lidam com importação, exportação, o atacado e a lavagem de dinheiro. Neste sentido, verifica-se que o alarde em torno do tráfico é bastante seletivo, incidindo especialmente sobre sua parcela mais pobre.

$\mathrm{O}$ autor esquematiza o tráfico em dois subsistemas distintos, que se interconectam. O primeiro seria o subsistema $I-E-A$ (importação-exportação-atacado) e o segundo seria o subsistema varejo. O subsistema I-E-A responde pelos grandes traficantes e facilitadores do tráfico. Nas palavras do autor:

Os verdadeiros grandes traficantes (importadores, atacadistas), assim como seus sócios ou parceiros (agentes envolvidos com a lavagem de dinheiro, com o financiamento de negócios escusos, com o transporte da droga, etc.), secundados pelos principais facilitadores do negócio em grande escala (funcionários de portos e aeroportos, policiais corruptos etc.), vinculam-se ao subsistema I-E-A. O subsistema I-E-Aé o principal responsável 
pela importação de drogas... assim como pela realização de contatos visando a reexportação... Além disso, o subsistema I-E-A é em grande parte responsável pelo abastecimento dos traficantes que operam no varejo (não só com drogas, mas também com armas). (Souza, 2005, p. 430)

O subsistema varejo corresponde àquele que tem destaque garantido na imprensa, cujas bases de apoio logístico funcionam em favelas e outros espaços segregados, englobando, também, a venda de drogas em boates, restaurantes, e mesmo nas ruas. $\mathrm{O}$ autor chama a atenção para o fato de que mesmo sendo menos importante em termos estratégicos e detendo a menor parte dos lucros em relação ao subsistema I-E-A, é justamente sobre o subsistema varejo que incidem as maiores parcelas de repressão e de punição - são estes os traficantes que geralmente morrem ou são presos. O subsistema varejo seria ainda relativamente autônomo em relação ao I-E-A, não compartilhando de sua organização. Como indícios para esta afirmação, o autor menciona a fragmentação territorial (cada quadrilha teria uma territorialidade) ou territorialidade descontínua, a violência crônica e os constantes conflitos entre grupos rivais.

Tomando como referência uma escala internacional, e não local, o subsistema varejo aparece apenas como a ponta mais frágil da rede do tráfico, que se estende até os grandes empresários da droga, os quais se aproveitariam das condições miseráveis que se impõem a maior parte da população favelada para recrutar mão-de-obra barata e facilmente substituível.

A partir da consideração da escala da cidade como um todo, do país e do mundo, abarcando os financiadores e todos aqueles que, sem morarem em favelas e sem se exporem diretamente, são os principais beneficiários do tráfico, é que se observa melhor, entretanto, o quanto a pobreza é funcional para o tráfico de drogas, o qual devora a juventude das favelas como mão-de-obra barata e descartável. (Souza, 2005, p. 439)

Este recrutamento de mão de obra barata e facilmente substituível também é observado na organização local do tráfico nas favelas. Os relatos de meninos entrevistados por MV Bill e Celso Athaíde (2006) no livro Falcão: Meninos do Tráfico sinalizam o aumento crescente da oferta de meninos, cada vez mais jovens, para os trabalhos no tráfico e a consequente diminuição dos ganhos semanais e mensais dos mesmos, demonstrando que o mito do acesso rápido e fácil a outras condições de vida, e possibilidade de consumo, é uma realidade vivida por muito poucos. Grande parte dos meninos que trabalha como Falcões nas lajes e vielas da favela não chegam a ganhar um salário mínimo e são facilmente descartados e substituídos pela própria organização local. O que podemos perceber é que a lógica capitalista neoliberal se (re)produz também em meio a esta realidade.

Souza (2005) aponta ainda que a falta de engajamento por parte do Estado em setores de interesse social (como saúde e educação) vem constituindo um estímulo para que muitos pobres urbanos percebam o tráfico como estratégia de sobrevivência e mitifiquem os ganhos que com ele podem ter. Coimbra e Nascimento (2003) complementam a questão lembrando que a implantação de medidas neoliberais que começaram a surgir em nosso país na década de oitenta acarretaram sentimentos de insegurança, medo e pânico, articulados ao aumento da miséria e da exclusão. Em tal contexto, os jovens pobres comparecem, como os excluídos por excelência. A dificuldade de inserção no mercado de trabalho, as baixas perspectivas que a sociedade lhes oferece de um modo geral faz com que o mundo do crime seja uma opção para esses jovens - além de mais rentável que a maioria das outras ocupações disponíveis, também confere poder e status perante os demais.

Quanto às políticas de enfrentamento e incremento da repressão ao crime, e ao tráfico varejista em particular, que Souza (2005) define como militarização (cuja expressão máxima reside nas incursões policiais e até mesmo militares em áreas de atuação do tráfico varejista, como foi a Operação Rio³, em 1994) o autor adverte que o emprego exclusivo desta solução agrava o problema, "por gerar mais tensões e ressentimentos (atritos entre as forças policiais e militares e a população favelada) e retroalimentar a violência, ao invés de combater as suas causas mais profundas e enfrentar o subsistema I-E-A" (Souza, 2005, p. 450).

\section{Considerações finais}

Chegando ao final deste texto, analisemos o depoimento de um ex-capitão do Batalhão de Operações Policiais Especiais (BOPE) que ilustra bem o paradigma do Racismo de Estado e militarização do enfrentamento institucional relativo ao tráfico, presente no documentário Notícias de uma Guerra Particular, de 2005:

Você aperta esse morro aqui, eles espirram pelo lado, tu aperta do lado, eles espirram do outro, então é uma guerra sem fim. Por mais que toda noite você vá lá... Durante duas semanas, quase toda noite o BOPE matava um traficante ali. Apreendia uma pistola, matava um traficante, apreendia um fuzil, matava um traficante. Resolvia alguma coisa? Não resolvia nada. Para ele, o jovem lá, tem dezenas de jovens que não tão no movimento, que estão esperando a vez de entrar no movimento, e talvez esse outro que assuma, por ser mais novo... Nós vemos agora uma facção surgindo, o Comando Vermelho Jovem, o CVJ, né... Por ser mais novo, ele até tenha um ímpeto mais violento. (Pimentel, citado por Lund \& Salles, 2005)

Analisando esta fala, alguns elementos causam estranheza. A primeira coisa que salta ao leitor é a naturalidade com que se diz "toda noite o BOPE matava um traficante", uma verdadeira aberração constitucional, uma versão grotesca da pena de morte institucionalizada. E mais: ao se matar os traficantes, esperava-se resolver o problema, que não é resolvido porque eles “espirram por todo lado". Não há nenhum questionamento acerca das condições que fazem com que os traficantes espirrem por todo lado, muito menos do por quê existam tantos jovens que estão “esperando a vez de entrar no movimento". Não há críticas. A única solução proposta, explícita ou implicitamente neste discurso é o extermínio dos traficantes do varejo, corroborando a afirmação de Souza (2005) para quem a repressão pouco faz em relação ao subsistema I-E-A, os verdadeiros patrocinadores e chefes do tráfico. O final deste fragmento discursivo traz 
ainda um outro alerta, quando salienta o perigo atribuído ao jovem pobre, que talvez tenha um ímpeto "mais violento". Em última análise, nada mais é que a atribuição de uma essência a esta população jovem em particular que é justamente a da periculosidade, em moldes bastante semelhantes ao higienismo com características eugênicas (limpar a sociedade de seus degenerados). Sem dúvida, trata-se de uma base argumentativa que pode muito bem subsidiar campanhas para a redução da maioridade penal ou legitimar o desrespeito às prerrogativas do Estatuto da Criança e do Adolescente (ECA), afetando especialmente a população pobre. A fala deste policial nada mais é que uma expressão discursiva do Racismo de Estado, com potenciais (e graves) efeitos pragmáticos.

\section{Referências}

Agamben, G. (2003). Estado de Exceção. São Paulo: Boitempo.

Athaíde, C., \& Bill, MV. (2006). Falcão - meninos do tráfico. Rio de Janeiro: Objetiva.

Batista, V. M. (2003). Dificeis ganhos fáceis: drogas e juventude pobre no Rio de Janeiro ( $2^{\underline{a}}$ ed.) Rio de Janeiro: Revan.

Carvalho, S. (2006). Política criminal de drogas no Brasil: estudo criminológico e dogmático. ( $3^{\mathrm{a}}$ ed.) Rio de Janeiro: Lumen Júris

Coimbra, C., \& Nascimento, M. C. (2003). Jovens pobres: o mito da periculosidade. In P. C. P. Fraga \& J. A. S. Iulianelli (Orgs.), Jovens em tempo real (pp.19-37). Rio de Janeiro: DP\&A.

Deleuze, G. (1991). Foucault. São Paulo: Brasiliense.

Foucault, M. (1990). História da sexualidade, vol. I: a vontade de saber. (10를. M. Albuquerque \& J. A. Gilhon de Albuquerque, Trads.). Rio de Janeiro: Graal. (Texto original publicado em 1976)

Foucault, M. (2002). Os anormais: curso no Collège de France (1974-1975) (2 ed., E. Brandão, Trad.). São Paulo: Martins Fontes.
Foucault, M. (2005). Em defesa da sociedade: curso no Collège de France (19751976)(5aㅡ ed., M. E. Galvão, Trad.). São Paulo: Martins Fontes.

Lei $n$. 385 de 26 de dezembro de 1968. (1968, 26 de dezembro). Dá nova redação ao artigo 281 do Código Penal. Recuperado de http://www.jusbrasil.com.br/ legislacao/62076/decreto-lei-385-68

Lei $n .8072$ de 25 de julho de 1990. (1990, 25 de julho). Dispõe sobre os crimes hediondos, nos termos do art. $5^{\circ}$, inciso XLIII, da Constituição Federal, e determina outras providências. Recuperado de http:/www.jusbrasil.com.br/ legislacao/56321/lei-dos-crimes-hediondos-lei-8072-90

Lei n. 9.034 de 3 de maio de 1995. (1995, 3 de maio). Dispõe sobre a utilização de meios operacionais para a prevenção e repressão de ações praticadas por organizações criminosas. Recuperado de http://www.jusbrasil.com.br/ legislacao/33918/lei-do-crime-organizado-lei-9034-95

Magalhães, M. (2000). O narcotráfico (Coleção Folha Explica). São Paulo: Publifolha.

Lund, K., \& Salles, J. M. (Diretores). (2005). Noticias de uma guerra particular [DVD]. Brasil: Videofilmes.

Organização das Nações Unidas. (2008). Relatório Especial de execuções extrajudiciais, sumárias ou arbitrárias - Adendo: Missão ao Brasil pelo Dr. Philip Alston. Tradução não oficial do Documento ONU A/HRC/11/2/Add.2 providenciada pelo Projeto de Execuções Extrajudiciais do Centro de Direitos Humanos e Justiça Global, Faculdade de Direito da Universidade de Nova York. Recuperado de http://www.extrajudicialexecutions.org/

Constituição da República Federativa do Brasil. (1988, 5 de outubro). Recuperado de http://www.planalto.gov.br/ccivil_03/constituicao/constitui\%C3\%A7ao. htm

Schwarcz, L. M. (2004). O espetáculo das raças: cientistas, instituições no Brasil (1870-1930) (6 ${ }^{\mathrm{a}}$ ed.) São Paulo: Companhia das Letras.

Souza, M. L. (2005). As drogas e a "questão urbana" no Brasil: a dinâmica sócioespacial nas cidades brasileiras sob a influência do tráfico de tóxicos. In I. E. Castro, P. C. C., Gomes, \& R. L. Corrêa (Orgs.). Brasil: questões atuais da reorganização do território (pp. 419-468). Rio de Janeiro: Bertrand Brasil.

1. Interessante colocar que a primeira alteração sofrida na redação da Lei de Crimes Hediondos foi consequência direta da influência da mídia sobre a opinião pública brasileira em relação ao caso Daniela Perez - atriz da Rede Globo e filha da autora de telenovelas Glória Perez, assassinada pelo também ator Guilherme de Pádua em cumplicidade com sua esposa, Paula Thomaz. A mãe da atriz mobilizou, com uso extensivo da mídia, o apoio da população a fim de inserir na Lei de Crimes Hediondos também o homicídio qualificado. De fato, seu objetivo foi alcançado mediante emenda popular, em 1994.

2. De acordo com relatório das Organizações das Nações Unidas (2008) acerca das execuções extrajudiciais sumárias ou arbitrárias no Brasil, "as execuções extrajudiciais e a justiça dos vigilantes contam com o apoio de uma parte significativa da população que teme as elevadas taxas de criminalidade, e percebe que o sistema da justiça criminal é demasiado lento ao processar os criminosos" (p. 3).

3. A Operação Rio tratou-se de um convênio firmando em 1994 entre o Governo do Estado do Rio de Janeiro, o Governo Federal e as Forças Armadas com o fim de eliminar o tráfico dos morros cariocas.

Priscila Cravo Vianna, mestre em Psicologia pela Universidade Federal Fluminense, e técnico de nível superior na Fundação de Amparo à Pesquisa do Estado do Rio de Janeiro. Endereço para correspondência: Rua Leopoldo Miguez, 129, apto 1001. Copacabana, Rio de Janeiro-RJ. CEP: 22060-020. E-mail: prisvianna@ gmail.com Claudia Elizabeth Abbês Baêta Neves, doutora em Psicologia Clínica pela Pontifícia Universidade Católica de São Paulo, pós-doutora em Educação pela Universidade Federal do Espírito Santo, é professora Associada I no Departamento de Psicologia da Universidade Federal Fluminense. E-mail: abbes@luma.ind.br 